\section{Commentary: Never let semantics get in the way of a good idea}

\author{
Ming Hao Guo, MD, and Fraser D. Rubens, MD, MSc
}

The Latin "hybrida," refers to "offspring of a tamed sow and a wild boar." In biology, it is commonly used to refer to animals and plants of heterogenous lineage. Its application is traditionally the same in technology. A hybrid car combines 2 different energy sources for propulsion. In cardiovascular medicine, hybrid revascularization represents the combination of 2 different strategies-percutaneous coronary intervention and coronary artery bypass grafting-to restore coronary circulation. Therefore, in its modern use, a hybrid refers to something that combines 2 distinctly different technologies with different mechanisms to achieve the same clinical outcome.

In this issue of JTCVS Techniques, Shah and colleagues ${ }^{2}$ provide a comprehensive summary of various configurations of extracorporeal membrane oxygenation (ECMO) circuits that can be used when a traditional circuit strategy does not adequately meet the patient's physiological demands. Importantly, the authors focus on strategies that augment ECMO with additional ECMO cannulas depending on the physiological need rather than with other shortterm mechanical circulatory adjuncts.

Over the years, numerous devices for short-term mechanical circulatory support, including the intra-aortic balloon pump, Impella, and TandemHeart, have been invented, studied, and put into clinical use. These devices are inherently different than ECMO, but all serve to augment cardiac output. When used as an adjunct to ECMO for left ventricular venting, these "hybrid" short-term mechanical

From the Division of Cardiac Surgery, University of Ottawa Heart Institute, Ottawa, Ontario, Canada.

Disclosures: The authors reported no conflicts of interest.

The Journal policy requires editors and reviewers to disclose conflicts of interest and to decline handling or reviewing manuscripts for which they may have a conflict of interest. The editors and reviewers of this article have no conflicts of interest.

Received for publication Feb 17, 2021; revisions received Feb 17, 2021; accepted for publication March 1, 2021; available ahead of print March 4, 2021.

Address for reprints: Fraser D. Rubens, MD, MSc, University of Ottawa Heart Institute, 3401-40 Ruskin St, Ottawa, Ontario, Canada K1Y 4W7 (E-mail: frubens@ ottawaheart.ca).

JTCVS Techniques 2021;8:88-9

2666-2507

Copyright (c) 2021 The Authors. Published by Elsevier Inc. on behalf of The American Association for Thoracic Surgery. This is an open access article under the CC BY-NCND license (http://creativecommons.org/licenses/by-nc-nd/4.0/).

https://doi.org/10.1016/j.xjtc.2021.03.001

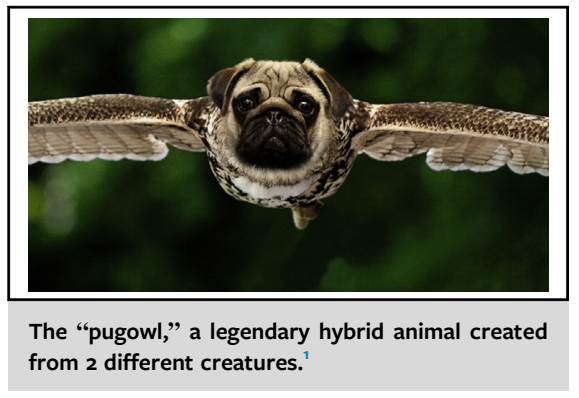

CENTRAL MESSAGE

The addition of cannulas for patients on extracorporeal membrane oxygenation (ECMO) should be called "extended" ECMO and should be in the armamentarium of heart failure surgeons.

circulatory support models have been shown to improve survival in patients with cardiogenic shock. ${ }^{3}$ These are truly hybrid technologies, as their applied mechanisms are completely different.

On the other hand, when additional ECMO configurations are added to existing circuits, often a different part of the cardiopulmonary physiological demand is augmented using the same technology as the original circuit. Therefore, venous-venoarterial, venovenous-arterial, or parallel ECMO circuits perhaps should be more appropriated called "extended" ECMO, as they represent the use of the same ECMO equipment and strategy to adequately meet physiological demands. As the authors describe, ECMO can be "extended" by the addition of cannulas to improve drainage, facilitate oxygenation, or increase cardiac output.

Both extended ECMO and hybrid strategies with shortterm mechanical circulatory support are important tools in our armamentarium for critically ill patients. Understanding both strategies will allow the clinician to tailor therapy to the patient's physiological needs and minimize complications. Shah and colleagues are to be commended for their effort in detailing the approaches and considerations for extended ECMO as a potential option in the management of these critically ill patients.

\section{References}

1. The "butterphant." Available at: https://www.reddit.com/r/HybridAnimals/ comments/3hsg8x/a_butterphant/. Accessed March 12, 2021. 
2. Shah A, Sagar D, Goerlich CE, Kaczorowski DJ. Hybrid and parallel extracorporeal membrane oxygenation circuits. J Thorac Cardiovasc Surg Tech. 2021;8:77-85.
3. Russo JJ, Aleksova N, Pitcher I, Couture E, Parlow S, Faraz M, et al. Left ventricular unloading during extracorporeal membrane oxygenation in patients with cardiogenic shock. J Am Coll Cardiol. 2019;73:654-62. 